\section{Age Determination of Wild-captured Milkfish Larvae as indicated by Daily Growth Increments of Otolith*1}

Short Paper
Since PANNella's work, ${ }^{1)}$ the age determination by daily growth increments of otolith has been successfully made for larvae and juvenile fishes. ${ }^{2-8)}$

During a histological observation of the sensory organs of milkfish larvae Chanos chanos (FORSSKÅL), an otolith with clear daily increments in the sections was incidentally found. The larvae were captured from the shore waters in Kumano, Tanega Is., Japan, from 28 July to 2 August with a specially designed seine net, and were fixed in Bourn's solution on the beach. They were transfered to $70 \%$ ethanol after one day fixation. The larvae were dehydrated with an ethanol series, embedded in paraffin, sectioned vertically along the body axis at 6 or $8 \mu \mathrm{m}$ thickness, stained with hematoxylin and eosin, mounted in Canada balsam, and observed under a differential interference contrast microscope.

In 8 out of 76 larvae examined, the increments of otolith could be counted accurately. No otolith was found in the larvae kept in $70 \%$ ethanol for more than two months. The otolith observed was a sagitta in the sacculus of inner ear. Each ring was counted at least five times in each otolith, along the axis from the nucleus to the posterior edge. Based on the results from TANAKA et al. ${ }^{\text {) }}$ unclear and narrow rings in the core region were not counted because they seemed to be formed during the embryonic stage. From the number of daily increments, the larvae $(12.5-14.0 \mathrm{~mm}$ in total length) captured in the shore waters on 1 August and 2 August were considered to be 18-20 days old. This coincided well with the speculation by Liao et al. ${ }^{10)}$ who successfuly reared the larvae from eggs.

The daily growth rate of otolith was variable. It decreased with days and was found to be very low after

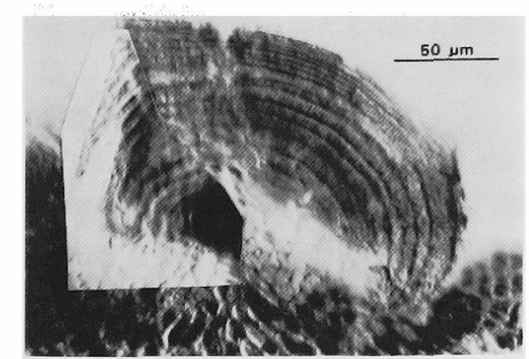

Fig. 1. Cross section of milkfish larva otolith. Total length of larva, $14.0 \mathrm{~mm}$. 20 daily growth increments.

(Accepted April 18, 1983)

*1 耳石によるサバヒー天然仔魚の日令

*2 川村軍藏・䨂山直樹: 鹿児島大学水産学部, 鹿児 島市下荒田 4 丁目 50-20

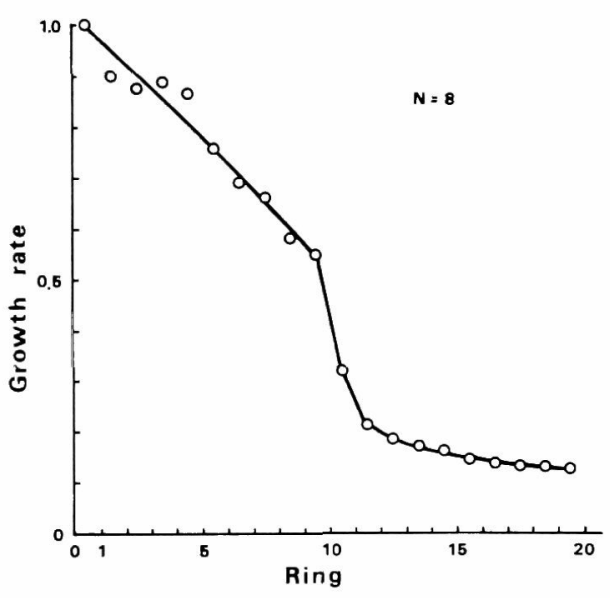

Fig. 2. Mean daily growth of each increment relative to the first increment.

the 10th or 11 th increments (Figs. 1 and 2). While the milkfish larvae occur seasonally in tremendous numbers in shore waters in the tropical and subtropical IndoPacific, the natural history of this species is scarcely known. Assuming that physiological conditions of an individual are imprinted on its otolith, several speculations on the ecology of the larvae in nature could be possible. However, no further analyses nor speculations on the ecology were attempted here because the number of larvae successfully examined was very small.

Gunzo KaWAmura and Naoki WashiYama*2 Faculty of Fisheries, Kagoshima University, 4-5020 Shimoarata, Kagoshima 890, Japan.

\section{References}

1) G. Pannella: Science, 173, 1124-1127 (1971).

2) E. B. Brothers, C. P. MATHews, and R. LASKer: Fish. Bull. U. S., 74, 1-8 (1976).

3) P. Struhsaker and J. H. Uchiyama: Fish. Bull. U. S., 74, 9-17 (1976).

4) R. C. Barkman: Trans. Am. Fish. Soc., 107, 790-792 (1978).

5) K. H. Wilson and D. A. Larkin: Can. J. Fish. Aquat. Sci., 37, 1497-1498 (1980).

6) R. E. Schmidt: Progr. Fish-Cult., 42, 78-80 (1980).

7) E. Stehensen: Dana, 1, 29-37 (1980).

8) D. W. Townsend and J. J. Graham: Fish. Bull. U. S., 79, 123-130 (1981).

9) K. Tanaka, Y. MugiYa, and J. Yamada: Fish Bull. U. S., 79, 459-466 (1981).

10) I.C. Liao, J.V. Juario, S. Kumagai, H. Nakajima, M. NATIVIDAD, and P. BurI: Aquaculture, 18, 75-93 (1979). 